Ti p60 regul at es M1- MP transcri pti on and i nvasi on of $\mathrm{gl}$ i obl ast oma cel I s through NF- K B pat hway

\begin{tabular}{|l|l|}
\hline 著者 & $\begin{array}{l}\text { Taki no Takahi sa, Nakada M t sut oshi , Li Zi chen, } \\
\text { Yoshi mot o Tai suke, Domot o Takahi ro, Sat o } \\
\text { H r oshi }\end{array}$ \\
\hline $\begin{array}{l}\text { j our nal or } \\
\text { publ i cat i on t i tl e }\end{array}$ & Cl i ni cal and Exper i nent al Net ast asi s \\
\hline vol une & 33 \\
\hline number & 1 \\
\hline page range & $45-52$ \\
\hline year & $2016-01-01$ \\
\hline URL & ht t p: //hdl . handl e. net $/ 2297 / 44820$ \\
\hline
\end{tabular}




\title{
Tip60 regulates MT1-MMP transcription and invasion of glioblastoma cells through NF-kB pathway
}

Takahisa Takino ${ }^{1,3}$, Mitsutoshi Nakada ${ }^{2}, Z^{2}$ chen $\mathrm{Li}^{1}$, Taisuke Yoshimoto ${ }^{1}$, Takahiro Domoto ${ }^{1}$, and Hiroshi Sato ${ }^{1,3}$

${ }^{1}$ Division of Molecular Virology and Oncology, Cancer Research Institute, Kanazawa University, Kakuma-machi, Kanazawa 920-1192, Japan

${ }^{2}$ Department of Neurosurgery, Graduate School of Medical Science, Kanazawa University, 13-1 Takara-machi, Kanazawa 920-0934, Japan

${ }^{3}$ To whom correspondence should be addressed: Division of Molecular Virology and Oncology, Cancer Research Institute, Kanazawa University, Kakuma-machi, Kanazawa 920-1192, Japan.

Phone: +81-76-264-6710; Fax: +81-76-234-4505

E-mail: ttakino@staff.kanazawa-u.ac.jp (T. Takino) or vhsato@staff.kanazawa-u.ac.jp (H. Sato)

\begin{abstract}
A histone acetyltransferase Tat-interacting protein $60 \mathrm{kDa}$ (Tip60) regulates the DNA damage response by acetylating histone and remodeling chromatin. In addition to histone acetyltransferase activity, Tip60 is known to regulate a variety of cellular functions, including gene expression, DNA damage response, cell migration and apoptosis. Lower expression of Tip60 is observed in lymphomas, melanomas, breast, colon, and lung cancer. It is widely accepted that Tip60 functions as a tumor suppressor. However, a role of Tip60 in gliomas still remains unclear. In this study, we investigated the role of Tip60 in the malignant behavior of human gliomas. By quantitative RT-PCR analysis using fresh human brain tumor tissues from 55 patients, we found that lower Tip60 expression and higher membrane-type 1 matrix metalloproteinase (MT1-MMP) expression are associated with advanced tumor grade in glioma tissues. Knockdown of Tip60 in glioblastoma cells promoted cell adhesion, spreading and MT1-MMP transcription and thereby invasion, which was suppressed by inhibition of MT1-MMP and nuclear factor-kappa B (NF-kB) activity. We demonstrate for the first time that tumor suppressor Tip60 down-regulates cell adhesion and MT1-MMP expression and thereby invasion of glioblastoma cells by suppressing NF-kB pathway.
\end{abstract}

Abbreviations: ECM, extracellular matrix; HAT, histone acetyltransferase; HDAC, histone deacetylase; MT1-MMP, membrane-type 1 matrix metalloproteinase; NF-kB, nuclear factor-kappa B; PBS, phosphate-buffered saline; QRT-PCR, quantitative real-time-PCR; Tip60, Tat-interacting protein $60 \mathrm{kDa}$;

Key words: Adhesion · Glioma $\cdot$ Invasion $\cdot$ MT1-MMP $\cdot$ NF-кB $\cdot$ Tip60

Article type: Research Paper 


\section{Introduction}

Tat-interacting protein $60 \mathrm{kDa}$ (Tip60 also KAT5) is a member of the MOZ, Ybf2/Sas3, Sas2, and Tip60

(MYST) family of histone acetyltransferase (HAT) and regulates the DNA damage response by acetylating histone and remodeling chromatin [1]. Besides HAT activity on chromatin remodeling, Tip60 possesses more divergent functions in many cellular processes. In transcriptional regulation, Tip60 can activate gene expression through its HAT activity, or act as a corepressor by the recruitment of histone deacetylase (HDAC) or through interactions with the transcriptional repressor. It plays crucial roles in cellular response to DNA damage by interacting with the kinase ataxia telangiectasia-mutated (ATM) and DNA-dependent protein kinase catalytic subunit (DNA-PKcs) [2]. Also, Tip60 is a major component of the p53 pathway. It acetylates a specific lysine residue in DNA-binding domain of p53 following DNA damage, resulting in the activation of a subset of target genes that trigger apoptosis $[3,4]$.

Loss of Tip60 is associated with a growing number of cancer types [5]. Lower expression of Tip60 is observed in lymphomas, melanomas, breast, colon, and lung cancer [5,6]. Down-regulation of Tip60 gene expression in colorectal cancer is correlated with increasing tumor size, metastasis, and tumor stage [7]. Ectopic expression of Tip60 suppresses but its knockdown promotes melanoma migration [8]. Tip60 overexpression up-regulates gene expression of metastasis suppressor CD82 (KAI), resulting in the decrease of invasion in metastatic cancer cells [9]. The recent study has demonstrated that CD82 interferes with MT1-MMP-mediated MMP-2 activation by unknown mechanism [10].

MT1-MMP, a first member of membrane-anchored MMP was originally identified as a tumor-specific 
MMP-2 activator [11-13], and is now known to activate MMP-13 and degrade a wide range of extracellular matrix (ECM) components, including type I, II, III collagen, laminins, and fibronectin (FN) [13]. This enzyme also processes and interacts with membrane-tethered proteins such as integrins and CD44. Among MMPs, MT1-MMP is most closely associated with the invasive phenotype of human tumors. The inhibition of MT1-MMP suppresses tumor cell invasion both in vitro and in vivo. [13-15]. Thus, MT1-MMP is considered to play a significant role in tumor progression.

To investigate the role of Tip60 in the malignant behavior of human gliomas, the expression level of Tip60 was evaluated as a function of tumor grade in 55 surgical specimens. Our data indicate that lower expression of Tip60 is significantly associated with enhanced MT1-MMP expression and higher tumor grade. We also show that Tip60 knockdown facilitates cell attachment, spreading and transcription of MT1-MMP, and thereby promotes invasion of glioblastoma cells. Our findings provide insight into the molecular mechanism by which Tip60 functions as a tumor suppressor. 


\section{Methods}

Cell culture and reagents

Human glioblastoma U87 cells were maintained in Dulbecco's modified Eagle's medium supplemented with 10\% FBS. Glass coverslips and FN were purchased from Asahi Techno Glass (Tokyo, Japan). A synthetic MMP inhibitor BB94 was a kind gift from the Kotobuki Pharmaceutical (Nagano, Japan). An anti-MT1-MMP antibody (Clone 222-3E12) was gifted by Daiichi Fine Chemicals (Toyama, Japan). NF-кB inhibitor BAY11-7082, PI3-K inhibitor LY294002, ROCK inhibitor Y27632, and MLCK inhibitor Blebbistatin were purchased from Merck Millipore (Temecula, CA, USA). The immunological reagents used were; anti-CD44, anti-integrin $\beta_{1}$, anti-integrin $\alpha_{v}$, anti-Tip60, and anti-p21 Cip antibodies (Santa Cruz Biotechnology, Santa Cruz, CA, USA); anti-Tip60, anti-integrin $\beta_{3}$, and anti-p53 antibodies (Merck Millipore); anti-N-cadherin and anti-paxillin antibodies (BD Biosciences, Bedford, MA, USA); an anti-tubulin antibody (Sigma-Aldrich, St Louis, MO, USA); DAPI, rhodamine-phalloidin, and Alexa Fluor-labeled secondary antibodies (Molecular Probes, Eugene, OR, USA).

Clinical samples and histology

Following informed consent, fresh human brain tumor tissues were obtained from 55 patients who underwent 
therapeutic removal of gliomas at Kanazawa University Hospital as approved by the Institutional Review Board.

Non-neoplastic control brain tissues were identified far from the tumor margins. The histoanalyses are based on the revised World Health Organization criteria [16]. The 55 gliomas consisted of 6 diffuse astrocytomas, 9 anaplastic astrocytomas, and 40 glioblastomas. All of the tumor tissues were obtained at primary resection, and none of the patients had been subjected to chemotherapy or radiation therapy before resection. Tissue samples were obtained and immediately frozen in liquid nitrogen. Samples were maintained at $-80^{\circ} \mathrm{C}$ until use.

Quantitative real-time-PCR (QRT-PCR)

Total RNA was isolated from fresh tumor tissues or cultured cells using the Sepasol-RNA I Super (Nacalai Tesque, Kyoto, Japan) according to the manufacture's procedure. Reverse transcription of RNA was performed using the QuantiTect Reverse Transcription Kit (Quiagen, Valencia, CA, USA). Gene expression was quantified by QRT-PCR on a LightCycler using MasterPLUS SYBR Green (Roche Diagnostics, Penzberg, Germany) as described previously [17]. PCR was done with the following primers for tip60 (NM_182710): forward (5'-CAGGACAGCTCTGATGGAATAC) and reverse (5'-AGAGGACAGGCAATGTGGTGAG); mt1-mmp (NM_004995): forward (5'-GGAATAACCAAGTGATGGATGG) and reverse (5'-TTGTTTCCACGGAAGAAGTAGG); $\quad$-actin $\quad$ (NM_001101): forward (5'-CTACAATGAGCTGCGTGTGGC) and reverse (5'-CAGGTCCAGACGCAGGATGGC). Hs_GAPDH_1_SG QuantiTect Primer (Qiagen) was used to monitor the amplification of GAPDH gene 
transcript as a control.

siRNA-mediated protein knockdown

The siRNA sequences were as follows: tip60, 5'-GUACGGCCGUAGUCUCAAGdTdT; tip60-2, 5'-ACGGAAGGUGGAGGUGGUUdTdT [4]; mt1-mmp, 5'-GCGAUGAAGUCUUCACUUAdTdT. As a control, siRNA duplex with an irrelevant sequence was used (Qiagen). U87 cells were transfected with $20 \mathrm{nM}$ of siRNA duplexes in Opti-MEM using Lipofectamine RNAiMAX (Invitrogen, Carlsbad, CA, USA) for $48 \mathrm{~h}$ and cultured for further $24 \mathrm{~h}$ in fresh medium. The cells $\left(1 \times 10^{5}\right.$ cells $\left./ \mathrm{ml}\right)$ were replated and cultured for $48 \mathrm{~h}$, and then analyzed.

Immunoblotting

Cells were lyzed in 10 mM Tris- $\mathrm{HCl}(\mathrm{pH} 7.5), 100 \mathrm{mM} \mathrm{NaCl}, 5 \mathrm{mM}$ EDTA, $2 \mathrm{mM} \mathrm{Na} \mathrm{VO}_{4}, 2 \mathrm{mM} \mathrm{NaF}$, and 1\% SDS after washing with phosphate-buffered saline (PBS). Protein concentration was determined using BCA assay (Pierce Thermo Scientific, Rockford, IL, USA). Cell lysates were separated by electrophoresis on SDS-polyacrylamide gels and transferred onto nitrocellulose membranes. Membranes were reacted with the indicated antibodies. The signal was monitored using a Li-COR Odyssey IR imaging system (Lincoln, NE, USA). 
Immunofluorescence staining

Cells were seeded and cultured on glass coverslips. After washing with PBS, the cells were fixed with $4 \%$ paraformaldehyde, permeabilized with $0.5 \%$ Triton X-100, stained with the indicated antibodies and then examined by confocal laser microscopy (Carl Zeiss, Jena, Germany).

\section{Gelatin zymography}

The conditioned media were analyzed with an SDS-polyacrylamide gel containing $0.1 \%$ gelatin as described previously [12,14]. Gelatinolytic activity of MMP-2 was detected as unstained bands on a blue background.

Cell attachment and spreading assay

For cell attachment assay, cells in suspension were allowed to adhere to FN-coated 96-well plates in complete media for $6 \mathrm{~h}$, and then stained with $1 \%$ crystal violet in methanol. After washing with PBS, the crystal violet was eluted with $10 \%$ acetic acid and measured by absorption at $560 \mathrm{~nm}$. For cell spreading assay, cells were suspended and allowed to adhere to FN-coated glass coverslips in complete media for $12 \mathrm{~h}$ and then stained. 
Cell invasion assay

Cell invasion was assayed using modified Boyden chambers consisting of Transwell membrane filters (Corning

Costar, Cambridge, MA, USA). Membranes were coated with 1mg/ml of Matrigel (BD Biosciences). U87 cells

$\left(2 \times 10^{5}\right.$ cells $)$ were suspended in $0.5 \% \mathrm{FBS} / \mathrm{DMEM}$ containing $2 \mathrm{mg} / \mathrm{ml}$ bovine serum albumin and poured added

to the upper chamber. Lower chambers were filled with $10 \%$ FBS/DMEM. After the cultivation incubation for

$20 \mathrm{~h}$, the number of crystal violet-stained cells on the lower surface was counted as described previously [15].

Statistics

Statistical analyses were done using two-tailed Mann-Whitney $U$ test. $P<0.05$ was considered significant. 


\section{Results}

Tip60 expression is down-regulated in glioblastoma tissues and cells

To evaluate the potential role of Tip60 in the malignant behavior of human gliomas, the expression levels of Tip60 and MT1MMP were evaluated as a function of tumor grade in 55 surgical specimens. The mRNA levels of Tip60 and MT1-MMP in human normal brain and gliomas were evaluated by QRT-PCR using $\beta$-actin mRNA as the internal reference for normalization (Fig. 1a). QRT-PCR analysis demonstrated that Tip60 mRNA levels (Tip60 mRNA: $\beta$-actin mRNA ratios) were significantly lower in glioblastoma tissues (mean $\pm \mathrm{SD}, 0.254 \pm$ $0.090 ; n=40)$ than in normal brain tissues $(0.799 \pm 0.143 ; P<0.001 ; n=8)$, diffuse astrocytoma tissues $(0.586$ $\pm 0.193 ; P<0.001 ; n=6)$ and anaplastic astrocytoma $(0.431 \pm 0.122 ; P<0.001 ; n=9 ;$ Fig. 1a). In contrast, the expression levels of MT1-MMP were significantly higher as tumor grade increased.

Furthermore, the expression levels of the Tip60 were lower in glioblastoma tissues obtained far from the necrosis of the tumors $(0.25$ - to 0.52 -fold $)$ than those in normal brain tissues resected from the margins of the tumors in 5 cases of glioblastoma (Fig. 1b). The expression levels of MT1-MMP were higher in glioblastoma tissues than in normal brain tissues. These results indicated the reverse correlation between Tip60 and MT1-MMP mRNA expression level in glioblastomas. 
In order to study the pathological significance of Tip60 down-regulation in glioblastoma cell lines, U87 cells were transfected with either control siRNA or siRNA for Tip60. Tip60 knock-downed cell showed a flat and large cell size compared with mock-transfected cells (Fig. 2a: left panel). Immunoblot analysis revealed that Tip60 knockdown reduces p21 ${ }^{\text {Cip1 }}$ expression and stimulates the expression of integrin $\beta_{3}$ and MT1-MMP (Fig. $2 b)$. The expression levels of $\mathrm{p} 53, \mathrm{~N}$-cadherin, integrin $\alpha_{\mathrm{v}}$ and $\beta_{1}$ were not changed. The expression of MT1-MMP protein was up-regulated by 4.1-fold in Tip60 knock-downed cells compared with mock-transfected cells (Fig. 2c). The expression level of MT1-MMP mRNA was examined by real-time PCR quantification. Tip60 knockdown up-regulated MT1-MMP mRNA expression by 3.3-fold compared with mock-transfected cells (Fig. 2d). In parallel with the increase of MT1-MMP level, gelatin zymography analysis showed that Tip60 knockdown promoted the activation of MMP-2 (Fig. 2ab), which was completely inhibited by double-knockdown with MT1-MMP (data not shown). MMP-2 expression levels were not significantly altered, and MMP-9 expression levels were not affected either as detected by gelatin zymography. These results show that Tip60 knockdown up-regulates MT1-MMP expression, resulting in the promotion of MMP-2 activation.

The an integrin $\alpha_{\vee} \beta_{3}$ is known to contribute to cell attachment to vitronectin and FN. Concomitant with the increase of integrin $\beta_{3}$ expression by Tip60 knockdown, cell adherence onto FN-coated plates was augmented (Fig. 2e). Immunofluorescence staining indicated that cell-ECM adhesions visualized by Paxillin staining and actin-stress fibers were well organized and formed in Tip60-silenced U87 cells when cells were plated onto 
FN-coated coverslips (Fig. 2f). These results show that the increase of integrin $\beta_{3}$ expression by Tip60 knockdown promotes cell attachment and spreading.

Tip60 knockdown promotes cell invasion

ECM degradation is one of important steps in invasion of brain tumors, in which MT1-MMP plays a central role $[18,19]$. The effect of Tip60 knockdown on invasion into Matrigel was tested. In parallel with the enhancement of MT1-MMP-mediated MMP-2 activation by Tip60 knockdown, invasion of U87 cells into Matrigel was drastically enhanced (Fig. 3a). BB94 treatment interfered with invasion of Tip60-silenced cells, accompanying with the blockade of MMP-2 activation (Fig. 3b). These results indicated that Tip60 knockdown promotes invasion of U87 cells into Matrigel by up-regulating MT1-MMP expression.

NFא-B inhibition reduces invasion of Tip60-silenced cells

To study the mechanism by which Tip60 knockdown up-regulates MT1-MMP expression, we tested the effect of a variety of reagents that were reported to suppress MT1-MMP expression, including PI3K inhibitor LY294002, ROCK inhibitor Y27632, Myosin II inhibitor Blebbistatin, and NFא-B inhibitor BAY11-7082, on MT1-MMP-mediated MMP-2 activation in Tip60 knock-downed cells. Only BAY11-7082 significantly suppressed MMP-2 activation in Tip60 knock-downed U87 cells (Fig. 4a), which was accompanied with the 
abrogation of MT1-MMP induction (Fig. 4bc). It also interfered with induction of integrin $\beta_{3}$ and CD44, which are well known target genes of NFK-B, in Tip60-silenced U87 cells. Thus, the enhanced invasive phenotype of Tip60 knock-downed U87 cell was impeded by BAY11-7082 treatment (Fig. 4d). These results suggest that Tip60 reduces invasive phenotype through suppression of NFK-B pathway. 


\section{Discussion}

The correlations between the reduced expression of Tip60 and tumor progression have been studied in many tumors. Recent studies have revealed that inactivation of Tip60 leads to defective DNA repair and increases cancer risk [20]. Overexpression of Tip60 up-regulates gene expression of metastasis suppressor CD82, resulting in decreased invasion of metastatic cancer cells into Matrigel [9]. In this study, we found that Tip60 expression level shows the reverse correlation with the tumor grade and MT1-MMP level in human glioma tissues (Fig. 1). Lower Tip60 expression may be associated with development and progression of gliomas.

Present study demonstrated that Tip60 knockdown up-regulates integrin $\beta_{3}$ expression, resulting in the enhancement of cell adhesion and spreading (Fig.2). Integrin $\alpha_{\mathrm{v}} \beta_{3}$ is expressed on the most aggressive tumor cells in many cancers including high-grade glioma [21], and its expression correlates with metastasis by recruiting c-Src to integrin $\beta_{3}$ [22]. Recent study has revealed that integrin $\beta_{3}$ is necessary and sufficient to

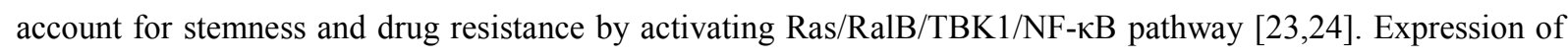
integrin $\beta_{3}$ is induced by a variety of factors, including hypoxia and inflammatory stress, and is down-regulated by HDAC inhibitor that activates HAT [25]. Tip60 functions not only as a co-activator but also as a co-repressor [1]. Tip60 may negatively regulate cellular adhesiveness at least in part through suppression of integrin $\beta_{3}$

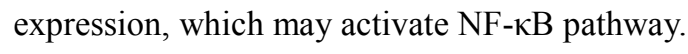

MMP-2 activation has been correlated with invasive behavior of many tumors [13]. Knockdown of Tip60 up-regulates the level of MT1-MMP mRNA and protein, resulting in the promotion of MMP-2 activation (Fig. 2). 
Thus, Tip60 knockdown promoted U87 cell invasion into Matrigel, which was blocked by MMP inhibitor (Fig.

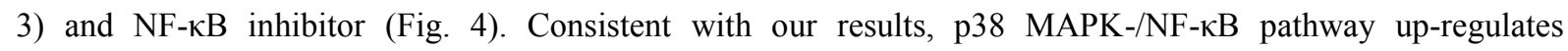
MT1-MMP expression [26,27]. Tip60 directly interacts and acetylates p53, and thus modulates its stability and

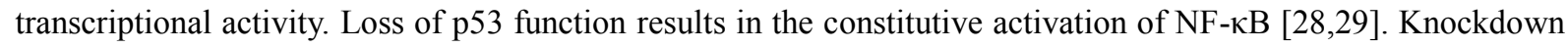
of Tip60 down-regulates the expression of p21 which is a target gene of p53 (Fig. 2). Tip60 depletion may up-regulate NF-אB activity by down-regulating p53 activity (Fig. 4e). Alternatively, Tip60 negatively regulates the gene expression by binding to signal transducers and activators of transcription 3 [30], cAMP response element-binding protein [31], and zinc finger E box-binding protein [32] which are all involved in tumor progression. Regulation of transcriptional factors by Tip60 may be a therapeutic approach for inhibition of tumor progression. Further studies are required to examine the molecular mechanism by which Tip60 regulates NF- $\kappa \mathrm{B}$ activity.

$\mathrm{NF}-\kappa \mathrm{B}$ is activated, and its target genes are overexpressed in glioblastoma tissues. The higher NF- $\kappa \mathrm{B}$ activity correlates with poor prognosis of glioblastoma patients [33]. We demonstrate here for the first time that tumor suppressor Tip60 negatively regulates cell adhesion and MT1-MMP expression in glioblastoma cells through NF- $\mathrm{B}$ pathway, resulting in suppression of invasiveness. It is widely accepted that either HDAC inhibition or HAT activation suppresses cancer cell invasion. Treatment with HDAC inhibitors reduces the MMP-2 expression and/or induces the expression of MMP inhibitors such as tissue inhibitor of metalloproteinases and

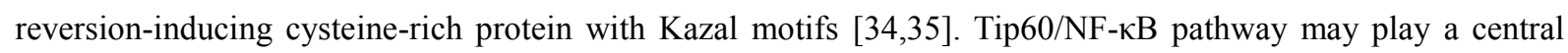
role in regulation of invasiveness of gliomas. 
In conclusion, our data indicate that Tip60 negatively regulates cell adhesion and MT1-MMP expression in glioblastoma cells through NF-kB pathway, which results in suppression of invasiveness. Tip60 may be a prognostic factor and a possible molecular target of gliomas.

Acknowledgments This work was supported by a KAKENHI Grant from the Japan Society for the Promotion of Science (JSPS)-Japan (grant no. 23590356 and 25460382).

Conflict of interest The authors declare that they have no conflict of interests. 


\section{References}

1. Squatrito M, Gorrini C, Amati B (2006) Tip60 in DNA damage response and growth control: many tricks in one HAT. Trend Cell Biol 16(9): 433-442. doi:10.1016/j.tcb.2006.07.007

2. Ikura T, Ogryzko VV, Grigoriev M, Groisman R, Wang J, Horikoshi M, Scully R, Qin J, Nakatani Y (2000) Involvement of the TIP60 histone acetylase complex in DNA repair and apoptosis. Cell 102(4): 463-473. doi:10.1016/S0092-8674(00)00051-9

3. Legube G, Linares LK, Tyteca S, Caron C, Scheffner M, Chevillard-Briet M, Trouche D (2004) Role of the histone acetyl transferase Tip60 in the p53 pathway. J Biol Chem 279(43):44825-44833. doi:10.1074/jbc.M407478200

4. Tang Y, Luo J, Zhang W, Gu W (2006) Tip60-dependent acetylation of p53 modulates the decision between cell-cycle arrest and apoptosis. Mol Cell 24(6): 827-839. doi:10.1016/j.molcel.2006.11.021

5. Gorrini C, Squatrito M, Luise C, Syed N, Perna D, Wark L, Martinato F, Sardella D, Verrecchia A, Bennett S, Confalonieri S, Cesaroni M, Marchesi F, Gasco M, Scanziani E, Capra M, Mai S, Nuciforo P, Crook T, Lough J, Amati B (2007) Tip60 is a haplo-imsufficient tumour suppressor required for an oncogene-induced DNA damage response. Nature 448(7157): 1063-1067. doi:10.1038/nature06055

6. Lleonart ME, Vidal F, Gallardo D, Diaz-Fuertes M, Rojo F, Cuatrecasas M, López-Vicente L, Kondoh H, Blanco C, Carnero A, Ramón y Cajal S (2006) New p53 related genes in human tumors: significant downregulation in colon and lung carcinomas. Oncol Rep 16(3): 603-608. doi: 10.3892/or.16.3.603 
7. Sakuraba k, Yasuda T, Sakata M, Kitamura YH, Shirahata A, Goto T, Mizukami H, Saito M, Ishibashi K, Kigawa G, Nemoto H, Sanada Y, Hibi K (2009) Down-regulation of Tip60 gene as a potential marker for the malignancy of colorectal cancer. Anticancer Res 29(10): 3953-3955.

8. Chen G, Cheng Y, Tang Y, Martinka M, Li G (2012) Role of Tip60 in human melanoma cell migration, metastasis, and patient survival. J Invest Dermatol 132(11): 2632-2641. doi: 10.1038/jid.2012.193

9. Kim JH, Kim B, Cai L, Choi HJ, Ohgi KA, Tran C, Chen C, Chung CH, Huber O, Rose DW, Sawyers CL, Rosenfeld MG, Baek SH (2005) Transcriptional regulation of a metastasis suppressor gene by Tip60 and $\beta$-catenin complex. Nature 434(7035): 921-926. doi:10.1038/nature03452

10. Schröder HM, Hoffmann S, Hecker M, Korff T, Ludwig T (2013) The tetraspanin network modulates MT1-MMP cell surface trafficking. Int J Biochem Cell Biol 45(6): 1133-1144. doi: 10.1016/j.biocel.2013.02.020

11. Sato H, Takino T, Okada Y, Cao J, Shinagawa A, Yamamoto E, Seiki M (1994) A matrix metalloproteinase expressed on the surface of invasive tumour cells. Nature 370(6484):61-65. doi:10.1038/370061a0

12. Takino T, Sato H, Shinagawa A, Seiki M (1995) Identification of the second membrane-type matrix metalloproteinase (MT-MMP-2) gene from a human placenta cDNA library. J Biol Chem 270(39): 23013-23020. doi: 10.1074/jbc.270.39.23013

13. Sato H, Takino T, Miyamori H (2005) Roles of membrane-type matrix metalloproteinase-1 in tumor invasion and metastasis. Cancer Sci 96(4): 212-217. doi: $10.1111 / \mathrm{j} .1349-7006.2005 .00039 . x$

14. Takino T, Miyamori H, Watanabe Y, Yoshioka K, Seiki M, Sato H (2004) Membrane type 1 matrix 
metalloproteinase regulates collagen-dependent mitogen-activated protein/extracellular signal-related kinase activation and cell migration, Cancer Res 64(3): 1044-1049. doi: 10.1158/0008-5472.CAN-03-1843

15. Takino T, Saeki H, Miyamori H, Kudo T, Sato H (2007) Inhibition of membrane-type 1 matrix metalloproteinase at cell-matrix adhesions. Cancer Res 67(24): 11621-11629. doi: 10.1158/0008-5472.CAN-07-5251

16. Louis DN, Ohgaki H, Wiestler OD, Cavenee WK, Burger PC, Jouvet A, Scheithauer BW, Kleihues P (2007) The 2007 WHO classification of tumours of the central nervous system. Acta Neuropathol 114(2): 97-109. doi:10.1007/s00401-007-0243-4

17. Yoshida Y, Nakada M, Sugimoto N, Harada T, Hayashi Y, Kita D, Uchiyama N, Hayashi Y, Yachie A, Takuwa Y, Hamada JI (2010) Sphingosine-1-phosphate receptor type 1 regulates glioma cell proliferation and correlates with patient survival. Int J Cancer 126(10): 2341-2352. doi: 10.1002/ijc.24933

18. Nakada M, Nakamura H, Ikeda E, Fujimoto N, Yamashita J, Sato H, Seiki M, Okada Y (1999) Expression and tissue localization of membrane-type 1,2, and 3 matrix metalloproteinases in human astrocytic tumors. Am J Pathol 154(2): 417-428. doi:10.1016/S0002-9440(10)65288-1

19. Annabi B, Lachambre MP, Plouffe K, Sartelet H, Béliveau R (2009) Modulation of invasive properties of CD133(+) glioblastoma stem cells: A role for MT1-MMP in bioactive lysophospholipid signaling. Mol Carcinog 48(10): 910-919. doi: 10.1002/mc.20541

20. Sun Y, Jiang X, Xu Y, Ayrapetov MK, Moreau LA, Whetstine JR, Price BD (2009) Histone H3 methylation links DNA damage detection to activation of the tumour suppressor Tip60. Nat Cell Biol 11(11): 1376-1382. 
doi: $10.1038 /$ ncb1982

21. Bello L, Francolini M, Marthyn P, Zhang J, Carroll RS, Nikas DC, Strasser JF, Villani R, Cheresh DA, Black PM (2001) $\alpha_{v} \beta_{3}$ and $\alpha_{v} \beta_{5}$ integrin expression in glioma periphery. Neurosurgery 49(2): 380-390.

22. Desgrosellier JS, Barnes LA, Shields DJ, Huang M, Lau SK, Prévost N, Tarin D, Shattil SJ, Cheresh DA (2009) An integrin $\alpha_{v} \beta_{3}$-c-Src oncogenic unit promotes anchorage-independence and tumor progression. Nat Med 15(10): 1163-1169. doi: 10.1038/nm.2009

23. Desgrosellier JS, Lesperance J, Seguin L, Gozo M, Kato S, Franovic A, Yebra M, Shattil SJ, Cheresh DA (2014) Integrin $\alpha_{v} \beta_{3}$ drives slug activation and stemness in the pregnant and neoplastic mammary gland. Dev Cell 30(3): 295-308. doi: 10.1016/j.devcel.2014.06.005

24. Seguin L, Kato S, Franovic A, Camargo MF, Lesperance J, Elliott KC, Yebra M, Mielgo A, Lowy AM, Husain H, Cascone T, Diao L, Wang J, Wistuba II, Heymach JV, Lippman SM, Desgrosellier JS, Anand S, Weis SM, Cheresh DA (2014) An integrin $\beta_{3}$-KRAS-RalB complex drives tumour stemness and resistance to EGFR inhibition. Nat Cell Biol 16(5): 457-468. doi: 10.1038/ncb2953

25. Wedel S, Hudak L, Seibel JM, Makarević J, Juengel E, Tsaur I, Wiesner C, Haferkamp A, Blaheta RA (2011) Impact of combined HDAC and mTOR inhibition on adhesion, migration and invasion of prostate cancer cells. Clin Exp Metastasis 28(5): 479-491. doi: 10.1007/s10585-011-9386-8

26. Han YP, Tuan TL, Wu H, Hughes M, Garner WL (2001) TNF- $\alpha$ stimulates activation of pro-MMP2 in human skin through NF-אB mediated induction of MT1-MMP. J Cell Sci 114(Pt1): 131-139.

27. Chowdhury A, Roy S, Chakraborti T, Dey K, Chakraborti S (2014) Activation of proMMP-2 by U46619 
occurs via involvement of p38MAPK-NFкB-MT1MMP signaling pathway in pulmonary artery smooth muscle cells. Mol Cell Biochem 385(1-2): 53-68. doi: 10.1007/s11010-013-1814-4

28. Kawauchi K, Araki K, Tobiume K, Tanaka N (2008) p53 regulates glucose metabolism through an IKK-NF-кB pathway and inhibits cell transformation. Nat Cell Biol 10(5): 611-618. doi: 10.1038/ncb1724

29. Guo AK Hou YY, Hirata H, Yamauchi S, Yip AK, Chiam KH, Tanaka N, Sawada Y, Kawauchi K (2014) Loss of p53 enhances NF-kB-dependent lamellipodia formation. J Cell Physiol 229(6):696-704. doi: $10.1002 /$ jcp. 24505

30. Xiao H, Chung J, Kao HY, Yang YC (2003) Tip60 is a co-repressor for STAT3. J Biol Chem 278(13): 11197-11204. doi:10.1074/jbc.M210816200

31. Gavaravarapu S, Kamine J (2000) Tip60 inhibits activation of CREB protein by protein kinase A. Biochem Biophys Res Commun 269(3): 758-766. doi:10.1006/bbrc.2000.2358

32. Hlubek F, Löhberg C, Meiler J, Jung A, Kirchner T, Brabletz T (2001) Tip60 is a cell type-specific transcriptional regulator. J Biochem 129(4): 635-641.

33. Bhat KP, Balasubramaniyan V, Vaillant B, Ezhilarasan R, Hummelink K, Hollingsworth F, Wani K, Heathcock L, James JD, Goodman LD, Conroy S, Long L, Lelic N, Wang S, Gumin J, Raj D, Kodama Y, Raghunathan A, Olar A, Joshi K, Pelloski CE, Heimberger A, Kim SH, Cahill DP, Rao G, Den Dunnen WF, Boddeke HW, Phillips HS, Nakano I, Lang FF, Colman H, Sulman EP, Aldape K (2013) Mesenchymal differentiation mediated by NF-kB promotes radiation resistance in glioblastoma. Cancer Cell 24(3): 331-346. doi: 10.1016/j.ccr.2013.08.001 
34. Ailenberg M, Silverman M (2002) Trichostatin A-hisotone deacetylase inhibitor with clinical therapeutic potential-is also a selective and potent inhibitor of gelatinase A expression. Biochem Biophys Res Commun 298(1): 110-115. doi:10.1016/S0006-291X(02)02420-8

35. Liu LT, Chang HC, Chiang LC, Hung WC (2003) Histone deacetylase inhibitor up-regulates RECK to inhibit MMP-2 activation and cancer cell invasion. Cancer Res 63(12): 3069-3072. 


\section{Figure Legends}

Fig. 1 Tip60 and MT1-MMP mRNA expression in barin tumors. a Tip60 (left) and MT1-MMP (right) mRNA levels of 55 clinical samples were analyzed by Quantitative RT-PCR as described in "Methods". NB, normal brain; LGA, low-grade astrocytomas; AA, anaplastic astrocytomas; GB, glioblastomas; *, $p<0.05 ; * *, p<0.01$; ***p $<0.001$. b Tip60 (left) and MT1-MMP (right) mRNA levels of tumor and normal brain tissues resected from the margins of the tumors in 5 cases of glioblastoma were analyzed as described above.

Fig. 2 Tip60 knockdown promotes cell attachment, spreading and MMP-2 activation. a U87 cells were transfected with control RNA (siScr) or Tip60 siRNA, and photos were taken at $48 \mathrm{~h}$ after replating. The cell lysates were analyzed by immunoblotting with anti-Tip60 or anti-tubulin antibody. The conditioned media was analyzed by gelatin zymography. b U87 cells were transfected with siRNA, and cell lysates were analyzed by immunoblotting with anti-Tip60, anti-p53, anti-p21 Cip1, anti-integrin $\beta_{3}\left(\operatorname{Int} \beta_{3}\right)$, anti-integrin $\beta_{1}\left(\operatorname{Int} \beta_{1}\right)$, anti-integrin $\alpha_{\mathrm{v}}\left(\operatorname{Int} \alpha_{\mathrm{v}}\right)$, anti-N-cadherin (Ncad), anti-MT1-MMP (MT1), or anti-tubulin antibody. The conditioned media was analyzed by gelatin zymography. c MT1-MMP level was evaluated by densitometric analysis of the immunoblots. MT1-MMP levels are normalized to that of cells transfected with control RNA. The error bars are standard deviations of the mean values obtained from three independent experiments. ${ }^{*}, p<$ 0.05. d mRNA was extracted from U87 cells transfected with siRNA as above, and was subjected to Quantitative RT-PCR as described in "Methods". The levels of mRNA were normalized to that of cells transfected with 
control RNA. The error bars are standard deviations of the mean values obtained from three independent experiments. ${ }^{*}, p<0.05$. e U87 cells transfected with siRNA were subjected to cell attachment assay to FN-coated culture plates as described in "Methods". The error bars are standard deviations of the mean values obtained from three independent experiments. ${ }^{*}, \mathrm{p}<0.05$ (compared to the siScr). $\mathbf{f}$ Cells were also adhered on the FN-coated coverslips for $12 \mathrm{~h}$ and stained with DAPI, rhodamine-phalloidin and anti-paxillin antibody. Scale bars, $20 \mu \mathrm{m}$.

Fig. 3 Tip60 knockdown promotes cell invasion. a U87 cells were transfected with siRNA for control or Tip60 for $72 \mathrm{~h}$ and then seeded onto transwell chambers coated with Matrigel and cultured for $20 \mathrm{~h}$ with or without BB94. Cells on the filter underside (Lower panel) were counted as described in "Methods". The error bars are standard deviations of the mean values obtained from three independent experiments. ${ }^{*}, \mathrm{p}<0.001$ (compared to the siScr). b Aliquots of conditioned media form upper chambers were analyzed by gelatin zymography.

Fig. 4 Tip60 regulates glioblastoma cell invasion through NF- $\kappa$ B pathway. a U87 cells transfected with siRNA for Tip60 were detached, kept in suspension for $1 \mathrm{~h}$, and seeded and cultured for $6 \mathrm{~h}$. Then, the cells were treated with MMP inhibitor BB94 $(2 \mu \mathrm{M})$, PI3-K inhibitor LY294002 (25 $\mu \mathrm{M})$, ROCK inhibitor Y27632 $(10 \mu \mathrm{M})$, MLCK inhibitor Blebbistatin $(10 \mu \mathrm{M})$, and NF- $\mathrm{B}$ inhibitor BAY-11-7082 $(7 \mu \mathrm{M})$ for $42 \mathrm{~h}$. The conditioned media was analyzed by gelatin zymography. b U87 cells were transfected with siRNA for control or Tip60, and then treated with BAY-11-7082 for $42 \mathrm{~h}$. The conditioned media was analyzed by gelatin zymography, and the 
cell lysate were analyzed by immunoblotting with anti-MT1-MMP, anti-integrin $\beta_{3}$ or anti-tubulin antibody. c Quantitative RT-PCR for mRNA expression of MT1-MMP was performed as described in "Methods". Expressions of these mRNA are normalized to that of cells transfected with control RNA. The error bars are standard deviations of the mean values obtained from three independent experiments. ${ }^{*}, p<0.05$. d U87 cells were transfected with siRNA for Tip60 and then seeded onto transwell chambers coated with Matrigel and cultured for $20 \mathrm{~h}$ with or without BAY-11-7082 $(5 \mu \mathrm{M})$. Cells on the filter underside were counted. Columns, mean; bars, SD; *p $<0.001$ (compared to the DMSO). e A model for invasion induced by Tip60 knockdown through NF- $\kappa \mathrm{B}$ activation. 
$\mathbf{a}$

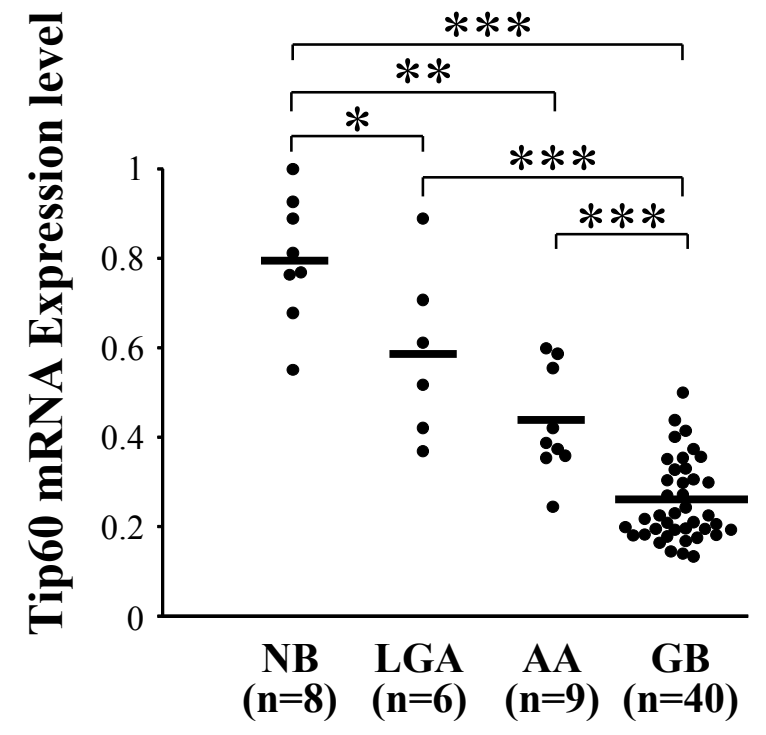

b

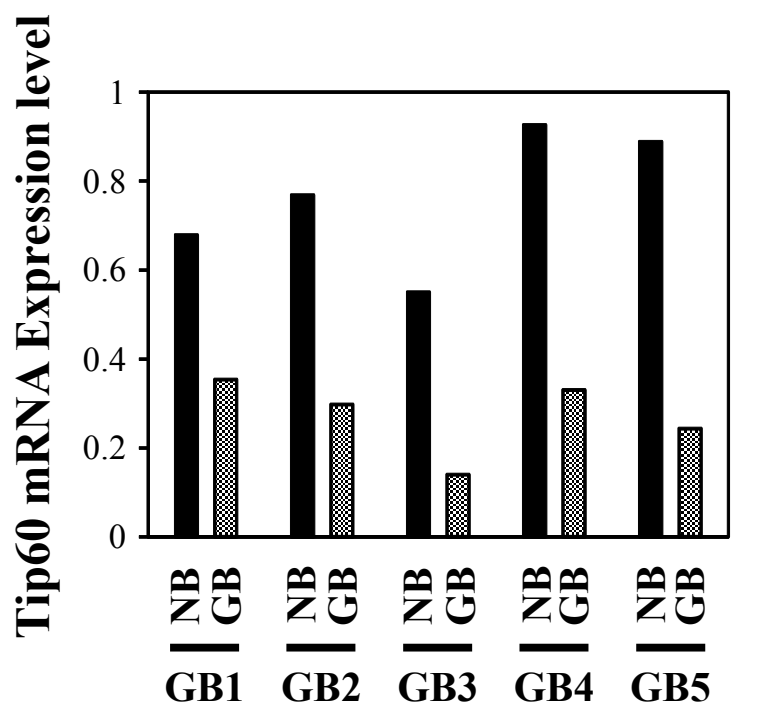

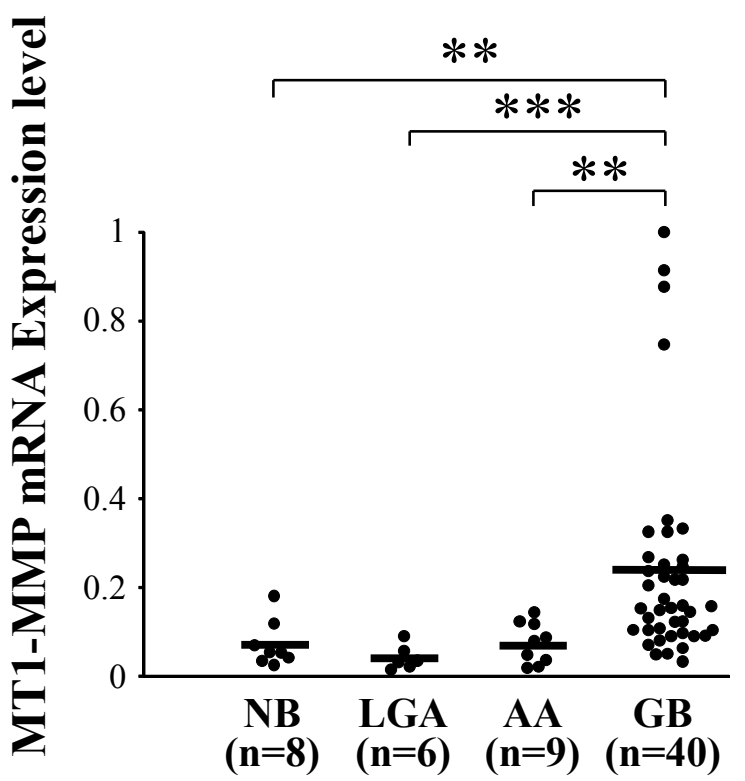

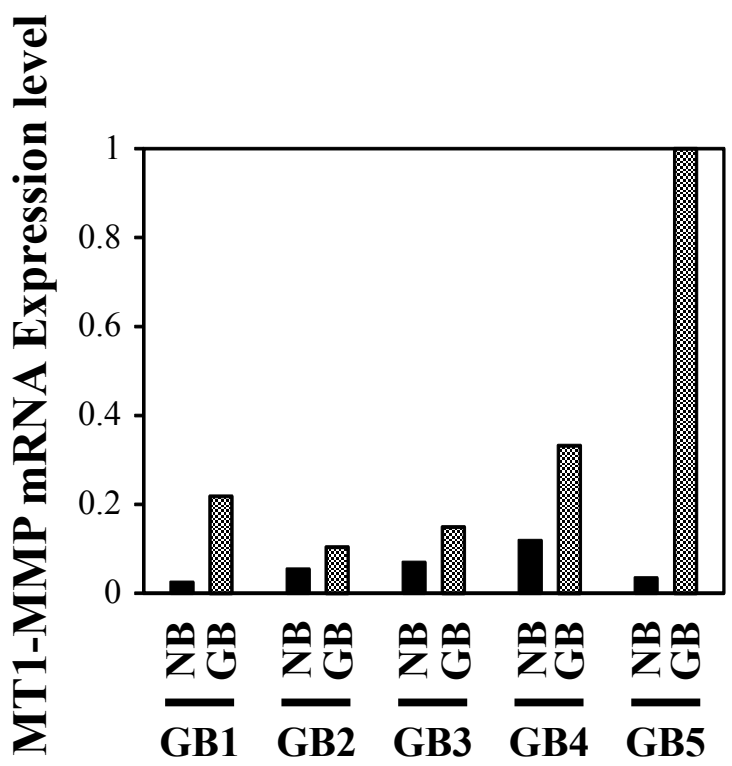




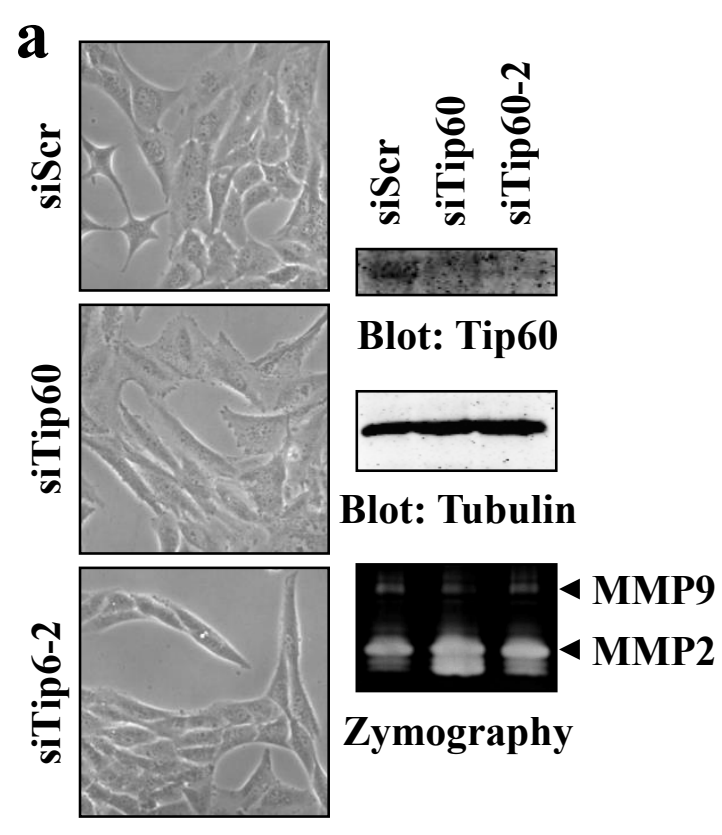

b $\begin{aligned} & \text { siTip60 }-+C \\ & \text { Blot: Tip60 }\end{aligned}$
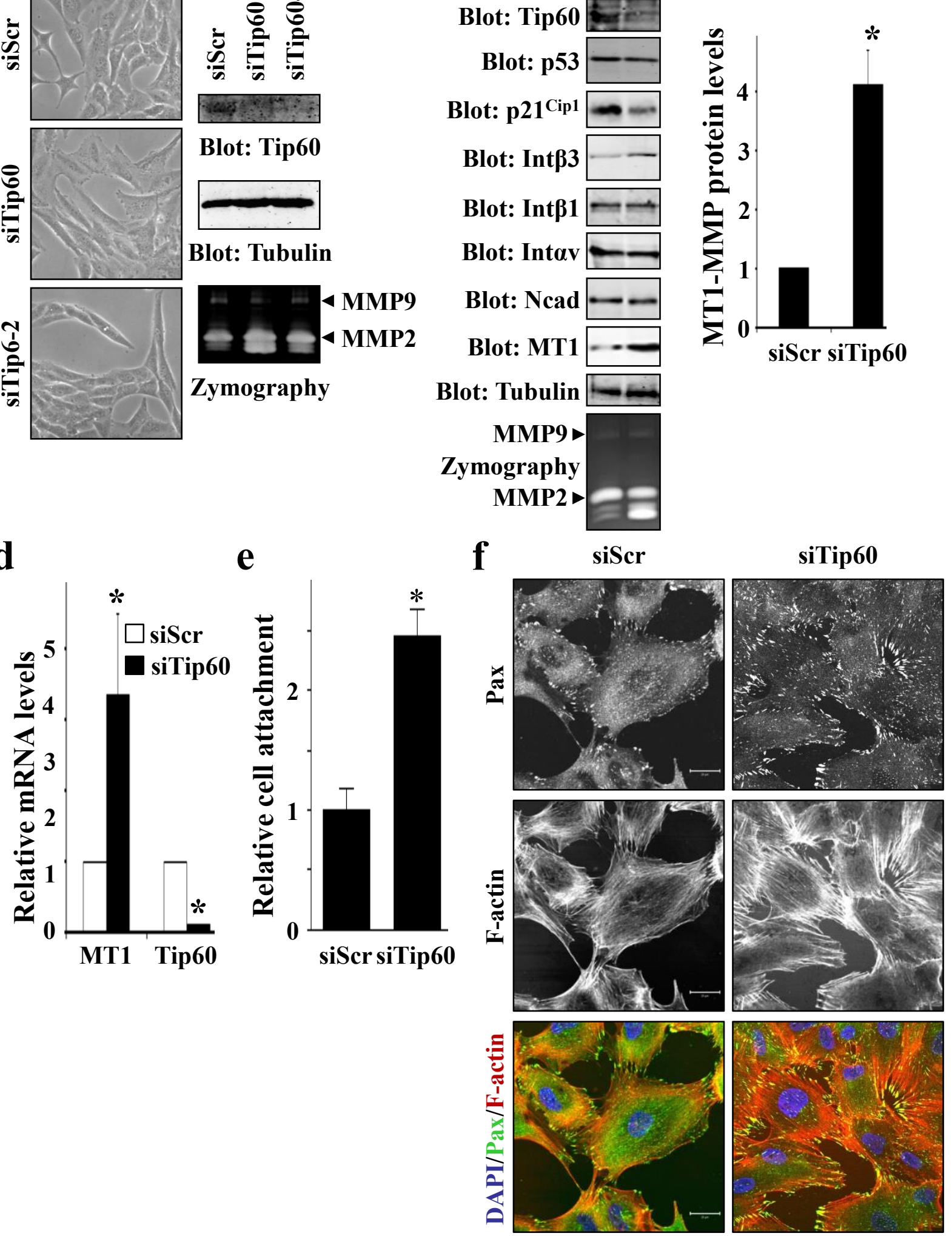


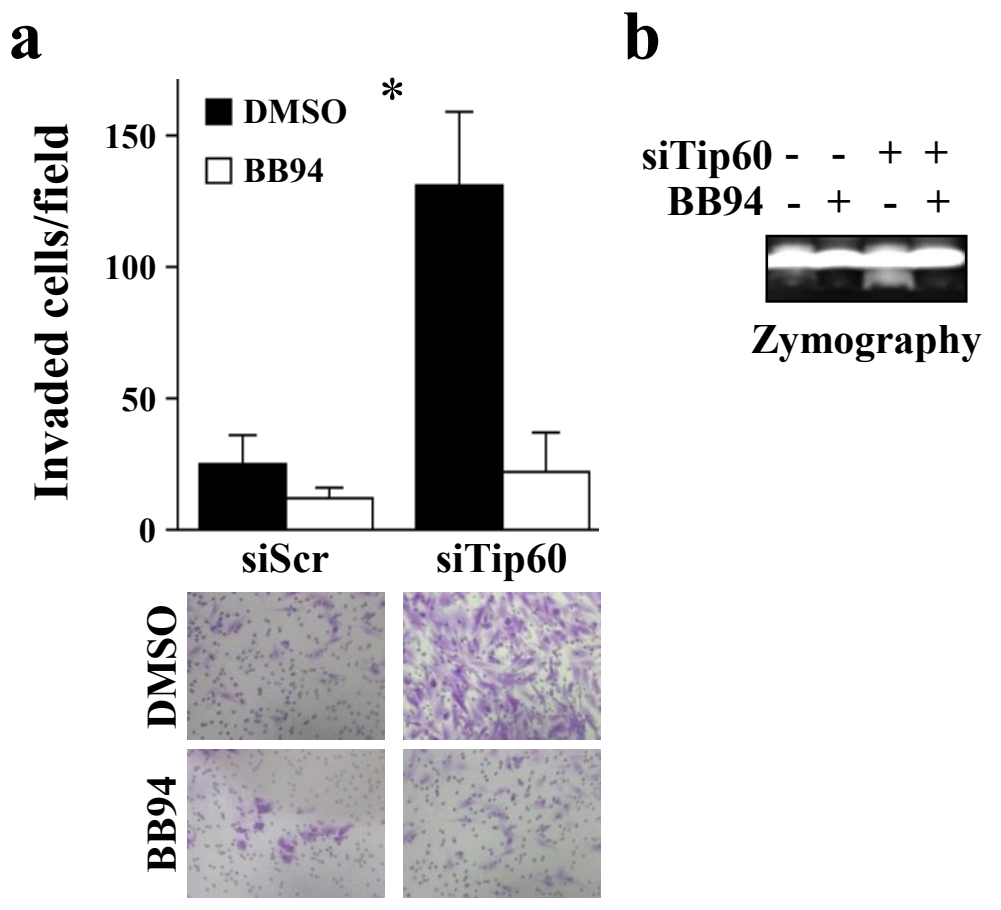


a

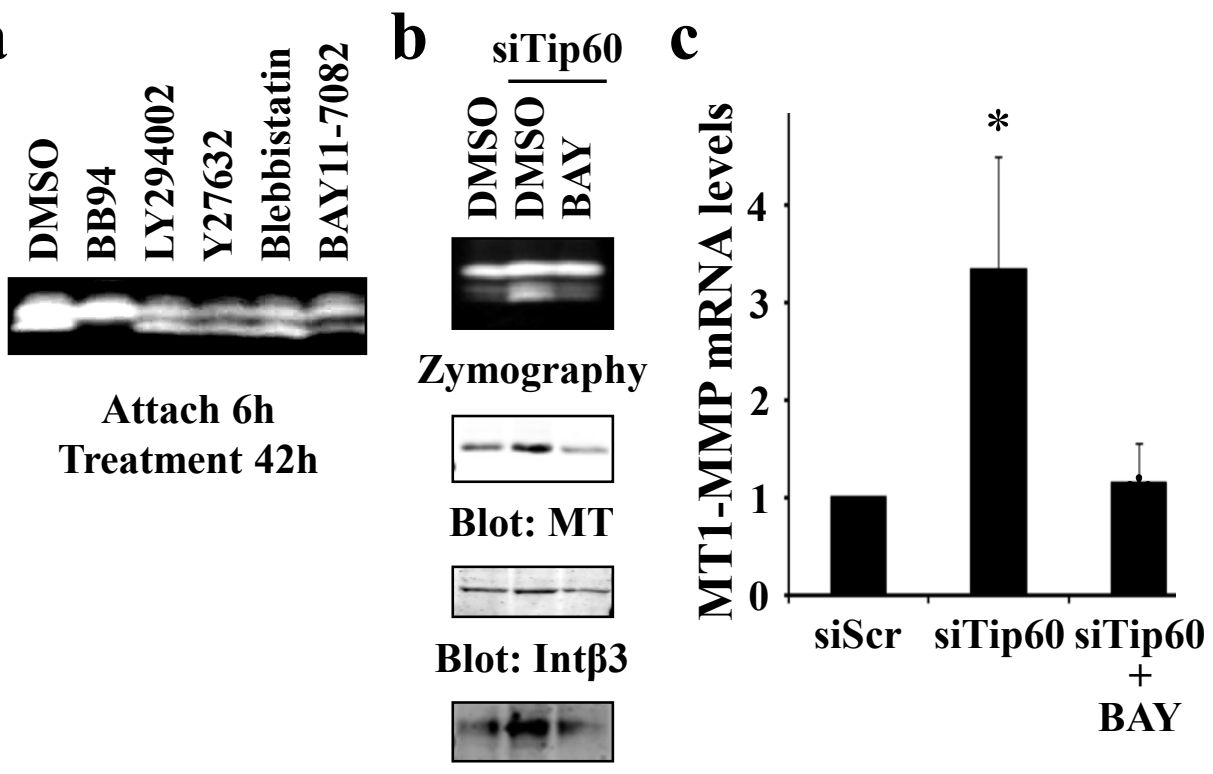

Blot: CD44

Blot: Tubulin

d

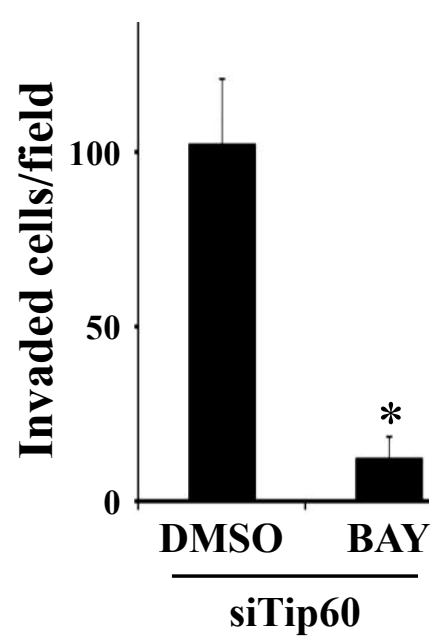

e

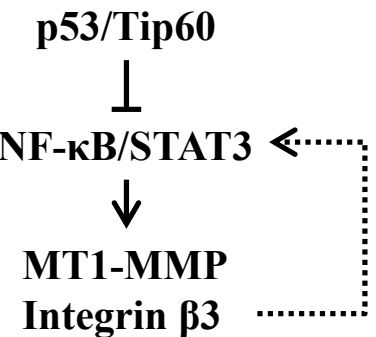

$\downarrow$

Invasion 